\title{
Calculation of Labyrinth Seals in the Secondary Air System of Aircraft Engine
}

\author{
Andrei Tisarev, Sergei Falaleev ${ }^{*}$ and Alexandr Vinogradov
}

Samara State Aerospace University, Samara, Russia

\begin{abstract}
The labyrinth seals perform the important functions in the aircraft engine systems operation, which aim to reduce the air leakages and the mutual system interference reduction. The calculation of the labyrinth seal characteristics is performed simply by using the analytical relationships or the modern tools of numerical analysis. However, the seal operation specificity within the system of operating engine secondary streams imposes some additional difficulties manifested in the rotor and stator elements deformation forming a gap. In this paper, we analyzed the formation cases of axis symmetric and asymmetric forms of labyrinth seal gaps. For the case of symmetrical cone gaps formation the correction factors were obtained by using the Fluent analysis to assess the seal characteristics with the conical form of the gaps, compared with the seal with cylindrical shape concentric gaps at the minimum radial clearance. The algorithm of axis symmetric seal deformation at the calculation of the engine secondary air system is described. The asymmetric components of deformations for the rotor and the high-pressure compressor housing are analyzed separately. The high rigidity of the elements contributed to the emergence of low level asymmetric deformation, allowing exclude them at the calculation of the seal characteristics.
\end{abstract}

Keywords: Deformation, eccentricity, labyrinth gap, misalignment of axes, stator ovalization, taper.

\section{INTRODUCTION}

The main elements of the internal air flow system, which are responsible for the flows separation with different parameters of the air and the leakage decrease from the flow part of the engine are the seals $[1,2]$. The labyrinth seals are the most common ones used in gas turbine engines, and their number may reach several tens in one engine. This is due to the numerous benefits of the labyrinth seals, such as simplicity, low maintenance costs, the absence of pressure drop restrictions and the low probability of the contamination with solid particles.

The increase of the gas turbine engine cycle parameters leads to higher levels of pressure and temperature in the airgas channel and in the internal cavities, respectively. Therefore, the problem of seal leakages escalates.

3 main methods may be named for the leak detection in the labyrinth seals:

1) semi-empirical method;

2) a numerical approach, with the use of the computational fluid dynamics (CFD);

3) measurement of leakages during the seal purge on the test rig.

These methods differ in material, labor and time costs. The complete rejection from the most expensive experimental studies is impossible currently, but there is a reduction of field tests trend due to the so-called numerical experiment performance. The most common of these methods is a semi-empirical approach due to its simplicity.

Stodol's [3], Martin's [4], Hodkinson's [5], Egli's [6], and other works are devoted to the leak detection in the labyrinth seals. A special role for leakage calculation is given to the experimental discharge coefficient, which depends on the seal design.

The discharge coefficient and the seal leakage may be determined with a standard set of parameters that describe the labyrinth seal geometry: $\delta$-a radial clearance, D-an average diameter of a gap, s-tooth pitch, h-tooth height, znumber of teeth, t-tooth thickness, $\gamma_{1}, \gamma_{2}$-tooth angles. Additional values for stepped labyrinth seals: $h_{\text {st }}$-step height and $\delta_{\mathrm{ax}}$-the distance from the tooth to the ledge. Additional values for honeycomb labyrinth seals: $\delta_{\text {ef }}$-effective gap and $L$-honeycomb diameter.

The leakages through the labyrinth seal are calculated via theoretical and empirical $\mathrm{G}_{\text {th }}$ leakages and an empirical flow coefficient $\mathrm{C}_{\Lambda}$.

$G=C_{\Lambda} \cdot G_{t h}$

The most common formulas of leakage determination are the theoretical formula described by Stodola

$G_{t h}=F \frac{p_{1}}{\sqrt{R T^{*}}} \sqrt{\frac{1-\left(\frac{p_{2}}{p_{1}}\right)^{2}}{z}}$

and Martin 


$$
G_{t h}=F \frac{p_{1}}{\sqrt{R T^{*}}} \sqrt{\frac{1-\left(\frac{p_{2}}{p_{1}}\right)^{2}}{z+\ln \left(\frac{p_{1}}{p_{2}}\right)}} .
$$

The flow coefficient in a smooth seal is defined as the discharge coefficient result in a step compaction $C_{\Lambda}$ st multiplied by a correction factor $\mathrm{K}_{\mathrm{sm} / \mathrm{st}}$, which takes into account the kinetic energy transfer in a smooth seal compared with a step one.

$C_{\Lambda}=K_{s m / s t} \cdot C_{\Lambda s t}$,

where

$C_{\Lambda s t}=0.7, K_{s m / s t}=\frac{C_{\Lambda s m}}{C_{\Lambda s t}}$.

The correction factor $\mathrm{K}_{\mathrm{sm} / \mathrm{st}}$ is the function of the teeth number $\mathrm{z}$ and $\delta / \mathrm{s}$ ratio and is defined according to the curves obtained by Egli [6].

The effect of cell inserts on the seal characteristics was estimated in the articles [7-9]. The flow coefficient change in the seal is taken into account by a correction factor

$K_{\text {h.c. }}=\frac{\mathrm{C}_{\Lambda, h . c .}}{\mathrm{C}_{\Lambda, s m .}}$,

which can be approximately determined by the formula

$K_{\text {h.c. }}=\frac{\delta_{m .}}{\delta_{\text {nom. }}}=\frac{\frac{1}{2}\left(\delta_{e f .}+\delta_{\text {nom. }}\right)}{\delta_{\text {nom. }}}$,

where

$\delta_{e f .}=\sqrt{\left(\frac{L-t}{2}\right)^{2}+\delta_{\text {nom. }}^{2}}$.

These dependences allow the seal calculation as a separate engine unit with a good accuracy. However, this set of parameters as a rule is not enough and it is necessary to expand during the seal consideration in the secondary air system. This is primarily due to the gap shape that is not left as the cylindrical and concentric one during the engine operation. Besides, such sealing elements as coatings and honeycombs are tested on wear, which also adversely affects the seal performance.

The seal analysis using CFD methods is not limited by the standard cylindrical concentric seal gaps, and allows to evaluate the sealing performance for any gap shape, obtained during the engine operation. The following issues shall be considered during the numerical analysis implementation:

- $\quad$ setting selection (stationary or non-stationary one)

- $\quad$ model dimension selection (2D or 3D),

- $\quad$ turbulence model selection

- $\quad$ element size choice,

- $\quad$ wall layer modeling.
Thus, two issues shall be solved to calculate the labyrinth seals with a deformed shape:

- deformation of the labyrinth gap determination, which is modeled according to the gap calculated area;

- $\quad$ seal characteristics determination.

\section{SEAL ELEMENT DEFORMATION DETERMI- NATION METHOD}

The radial clearance in the labyrinth seal has the greatest degree of influence on its flow characteristics, and the determination of its value is of significant importance during the parameters calculation in the internal engine cavities.

The value seal radial clearance is influenced by the following factors:

- temperature deformations of the engine elements;

- mechanical deformations of the centrifugal forces;

- mechanical deformations of the fluid pressure;

- mechanical deformations of aerodynamic and thrust load impact;

- $\quad$ axial movements of the rotor elements.

The shape of the labyrinth seal gap during operation, as a rule, does not correspond to the mounting state. One may distinguish the following types of labyrinth seal gap forms: axis symmetric (cylindrical and conical gaps) and asymmetric (cylindrical eccentric with skewed axes and the gap with the stator ovalization).

The asymmetric shape of the gap is formed due to the circumferential non-uniformity of the rotor or stator element deformations due to the following types of loading: an uneven circumferential distribution of temperature fields, the weight of moving and stationary elements, aerodynamic and thrust loads.

The determination of the gap shape with asymmetric deformations is determined by solving three-dimensional problems of heat transfer and stress-strain state of the engine design.

One may define the following asymmetric gap shapes:

eccentric cylindrical gap

skewed axes gap

the gap with the stator ovalization.

The calculation of the labyrinth seals with eccentricity is described in $[10,11]$.

The main cause of the axis misalignment are the deflections of moving and stationary parts of the engine under the action of gravity at different element stiffness. The following factors influence significantly on the deflection magnitude: the longitudinal distribution of the rotor inertiastiff characteristics, the location, the type of supports and clamping devices, their circumferential stiffness. At that, the translational flexibility of the rotor supports have little effect and they may be ignored. The flexural rigidity of the rotor may be influenced by various design features such as axial and radial interferences, joint stiffness and the tightening torques of the group bolt connections, nonlinear contact- 
friction interactions between the power circuit components, etc.

At the impact of force the engine cases are deformed and the stator ovalization occurs. These distortions should be considered when the design radial gap is assigned, which leads to its increase. The ovalization occurs due to the effect of asymmetric and axisymmetric loads on the case. At the transmission of attractive force the power flow comes to the engine attachment points. The transverse forces and the bending moment that deform the case appear. Also, the lack of axial symmetry in the design (for example a longitudinal gap) allows the ovalization appearance even at axis symmetric stresses, such as pressure and convective heat exchange conditions. The main contribution to the deformation pattern is made by the engine mount scheme. It depends on the engine location, its type and thrust class.

At the combined case ovalization, the case and rotor deflection under the gravity force and the eccentricity of the seal rings a complex spatial form of the gap is formed, the calculation of which is difficult to realize with the use of correction coefficients due to the individual factors interference. Each of the factors has a certain influence on the leakages through the seal. Some factors may have a significant impact, the others may be neglected.

The rotor and stator deformation is determined separately with respect to each other on the model of a high-pressure compressor cascade of an aircraft engine.

The rotor asymmetric deformation tends to occur due to the sag under its own weight. This problem may be solved by using the generalized flat axis symmetric finite element, which differs from the harmonic components by the introduction of Fourier series in the shape functions, which allow the to apply asymmetrical loads and boundary conditions in calculations.

The compressor rotor deflection change is shown step by step with Fig. (1).

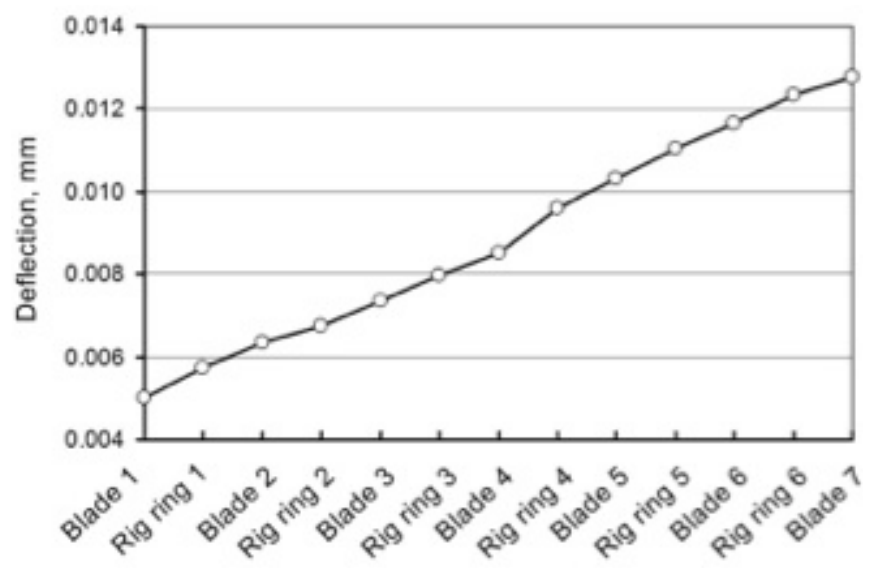

Fig. (1). High pressure compressor rotor deflections of an engine under its own weight.

According to the deformation determination results one may conclude that the high pressure rotor of a test engine has a high flexural stiffness, and the rotor deflections under the action of gravity do not exceed $17 \mathrm{mcm}$, which makes a minor contribution to the gap shape change of the labyrinth seals.
The engine cases may be represented in the form of variable thickness shells, and the attachment points may be represented in the form of different sections rods. The engine case model is shown by Fig. (2).

The engine is mounted under the aircraft wing by a pylon at two mounting zones-the front zone is located on the middle support and consists of three rods, two in the upper vertical plane, one in a horizontal plane to the right. Two rods of rear engine mount are located in a horizontal plane of the turbine support.

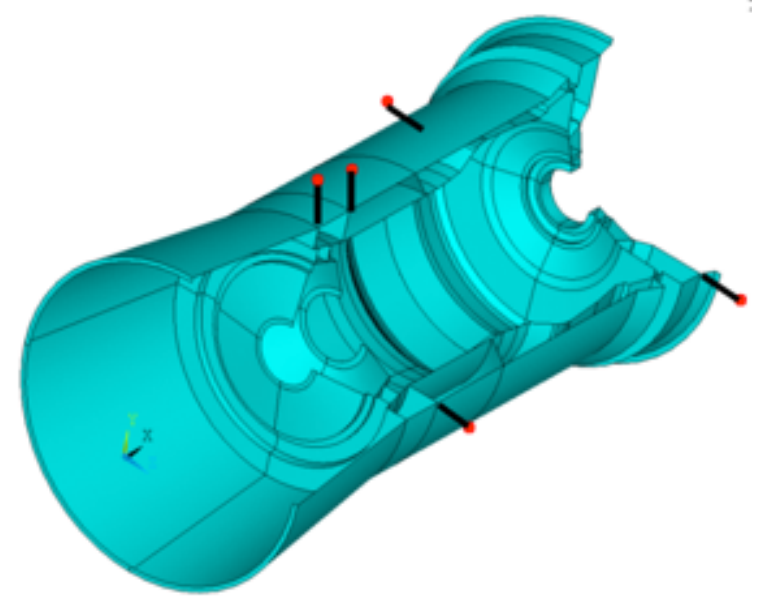

Fig. (2). Engine mount scheme.

The model fixation is performed in the units corresponding to the centers of the spherical bearings for the rod mounting connection elements to the engine in the direction to the rods. The model loading is provided by local application of evenly distributed forces around the circumference of the axis (in the amount of tractive force components) and transverse (in the amount of constituent components of the aerodynamic forces or gyroscopic moments), as well as by the application of acceleration components to the model corresponding to operational overloads. Besides, the bearing modeling forces are applied according to the rotor weight.

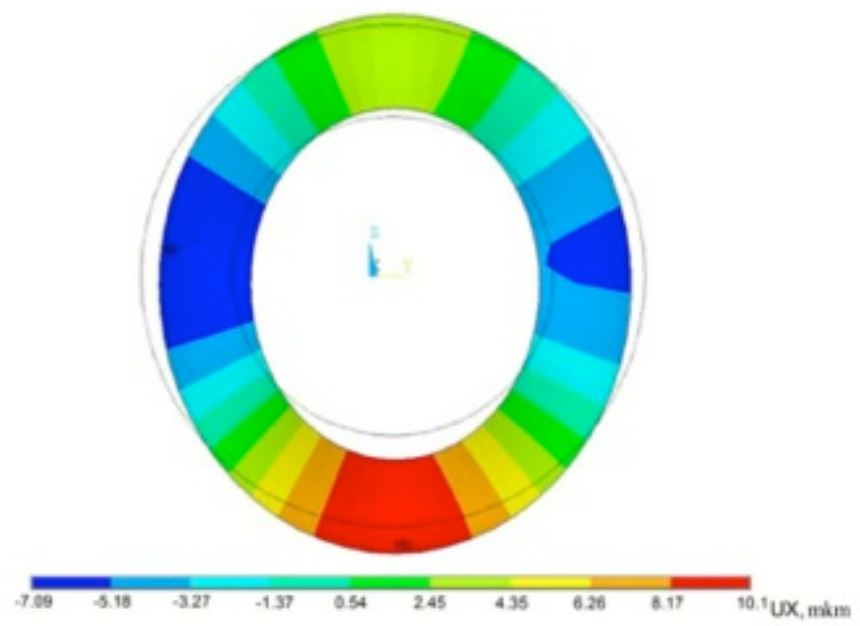

Fig. (3). Radial displacements image on support wall.

Thus, Fig. (3) shows that for the high pressure cascade of the engine asymmetric radial compressor case deformations 
in the support area reach $10 \mathrm{mcm}$ that also makes a minor contribution to the form deformation of a labyrinth seal gap.

During the first operating cycles of the engine the rotor and stator elements lapping occurs (see. Fig. 4), which leads to the seal flow characteristics change $[12,13]$. The axial and radial movements of labyrinth seal teeth sometimes lead to the groove formation of different depths and widths in operating coatings or honeycomb inserts. In some cases, the tip of the tip of labyrinth seal teeth is located inside grooves. Such a location corresponds to the negative radial clearance [14].

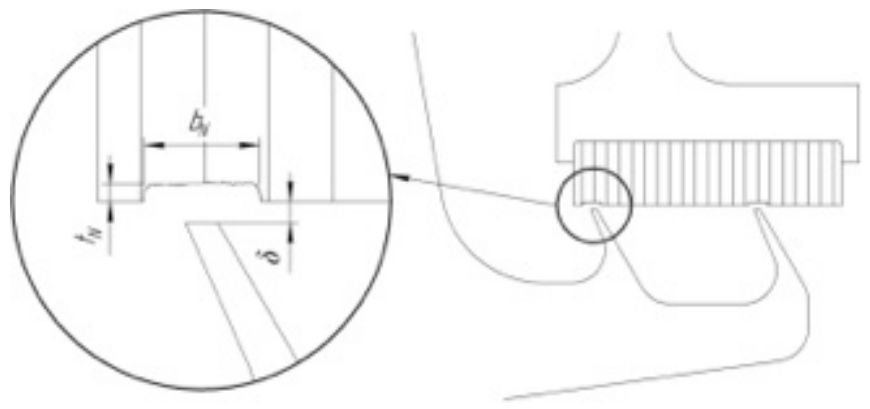

Fig. (4). Honeycomb insert grooves.

The grooves in the coatings and honeycomb inserts may also be formed by the rotor transverse oscillations [15]. The process of rotor transition through the critical frequencies may be accompanied by the vibration amplitudes increase, which may lead to the case touches with labyrinth seal edges and the cutting of coverings.

Of all the forms seal gaps the sealing performance may be assessed only for concentric cylindrical gap with the available analytical dependences. It is necessary to introduce the additional correction factors in equations or to simulate the seal assembly in computational gas dynamics programs to calculate the characteristics of a seal with a distorted form.

\section{CALCULATION OF LABYRINTH SEAL CHARACTERISTICS WITH AXIS SYMMETRIC GAP SHAPE}

The radial and axial axis symmetric sealing elements displacement during an engine operation leads to the following cases of labyrinth seal gap deformation:

- $\quad$ uniform change of the radial clearance along the seal length [16-18];

- $\quad$ non-uniform radial deformations of the seal elements along the gap length, leading to the formation of the labyrinth gap taper;

- axial displacements of sealing elements relative to each other that lead to the individual teeth loss by the operational area $[19,20]$.

The determination of the working radial clearance and the taper seal may be performed in an axis symmetric formulation of the heat exchange problem and the engine stress-strain state [21, 22]. The evaluation of sealing gaps is performed in the engine from the following loading factors: the distribution of temperature fields in details, the pressure of air or gas on the cases, the centrifugal force of the rotor and the axial force in the blades.
To assess the taper seal the dimensionless parameter of taper relative to the minimum value of the radial clearance $\delta_{\min }$ is used

$$
\Delta=\frac{\delta_{\max }-\delta_{\min }}{\delta_{\min }} .
$$

It should be noted that the gap taper may be of two types: convergent (the air flow direction is indicated by the solid line in Fig. 1) and the diffuser (the air flow direction is shown by a dotted line in Fig. 5).

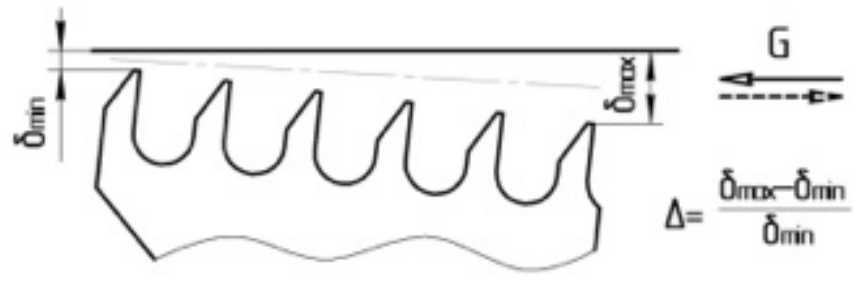

Fig. (5). Taper seal value.

The taper factor is introduced to consider the taper parameter influence on the sealing characteristics

$$
K_{\Delta}=\frac{\delta_{e f . \Delta}}{\delta_{e f .}}
$$

where $\delta_{\text {ef. }}$ is the effective clearance the seal cylindrical gap;

$\delta_{\text {ef. } \Delta}$-labyrinth seal effective clearance with a tapered gap.

Note that $\delta_{e f .}=\delta \cdot C_{\Lambda}$, where $\delta$ is operating radial clearance; $\mathrm{C}_{\Lambda}$-flow coefficient.

In determining $K_{\Delta}$ as radial clearance and tapered cylindrical gap the minimum radial clearance is accepted, i.e. $\delta_{\Delta}=\delta_{\min }$ to determine $\mathrm{K}_{\Delta}$ as the radial clearance of a tapered and cylindrical gap.

Thus, the Stodola formula determining the leakage through the labyrinth seal, taking into account the gap taper takes the following form:

$$
G=K_{\Delta} \cdot C_{\Lambda} \cdot F_{\min } \cdot \frac{p_{1}}{\sqrt{R T_{1}}} \sqrt{\frac{1-\pi_{y}^{2}}{z}},
$$

where $F_{\min }=\pi \cdot D_{m} \cdot \delta_{\min }$ is the area of the gap minimum cross section above the labyrinth tooth.

The Fluent was used. The stationary setting (Steady) was chosen for calculation. The Axisymmetric Swirl type, that takes into account the flow rotation due to the rotor presence was used as a two-dimensional model.

The method of grid convergence (GGI method) described in [23] was used to assess the grid quality, namely the influence of the grid sampling on the calculation results. For the subsequent computational studies the grid consisting of 164231 elements was chosen, since the grid error coefficients were obtained at the amount of less than $1 \%$.

Near the wall the boundary layer is modeled with a number of elements equal to 10 by thickness and the growth factor 1.2. The total thickness of the boundary layer ranged from 4 microns (on the teeth walls) to 150 microns (at the teeth inlet and outlet). This led to the values of $y^{+}=0.9 \ldots 6$. 
The air is considered as an ideal gas, the viscosity is calculated according to the Sutherland formulas.

$k-\varepsilon$ model with enhanced wall functions is chosen as the turbulence model.

\section{RESULTS}

The obtained results indicate that the seal gap taper effect is substantially increased with the pressure drop on the seal (Fig. 6).

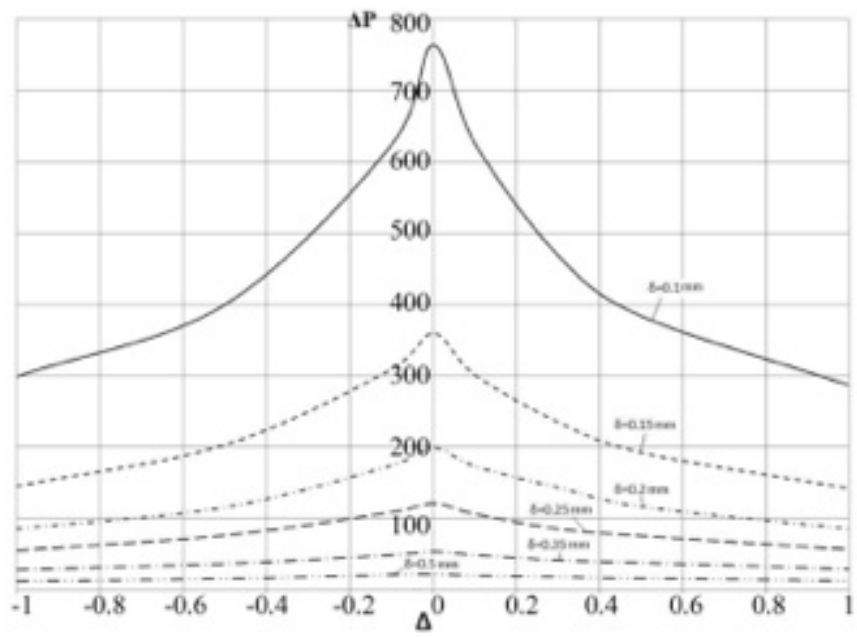

Fig. (6). Pressure drop dependence on the taper seal.

The calculations of the labyrinth seal at different values of its radial clearance were carried out by CFD method. The comparison of the results obtained in the computational gas dynamics system was carried out with analytical dependences, linking the pressure flow and drop on the seal (Fig. 7).

The following methods were selected for comparison: Stodol's, Martin's method and the method of seal characteristics calculation proposed by CIAM. The Stodol's, Martin's method and the flow coefficient for the step seal was 0.7 [1], and the estimate coefficient of the flow increase in a smooth seal $\mathrm{S}_{\Lambda \mathrm{gl}} / \mathrm{S}_{\Lambda \mathrm{st}}$ is determined by the Egli curves, approximated by the dependence [1].

$\frac{C_{\Lambda s m}}{C_{\Lambda s t}}=1+A \cdot\left(\frac{\delta}{h}\right)^{m}$,

where $A=0.85 \cdot z^{0.94}$

$m=0.52 \cdot z^{0.21}$

The closest to CFD calculation results are obtained by the method developed in CIAM: for the operating range of the labyrinth seals $0.3 \ldots 0.5 \mathrm{MPa}$ its error is less than $13 \%$. This may be explained by the fact that this method considers more geometric features of the labyrinth than the other two.

As a result, the dependences of the seal discharge coefficient $\mathrm{S}_{\Lambda}$ from the pressure drop are developed $\pi_{\mathrm{u}}=$ $\mathrm{p}_{1} / \mathrm{p}_{2}$ for different values of the gap taper parameter (Fig. 8). Fig. (8a) shows the results for the diffuser gap, and Fig. (8b) shows the results for the converging gap. Then the dependences of taper ratio $\mathrm{K}_{\Delta}$ were developed for different pressure drops on the seal (Fig. 9). Fig. (9a) shows the results for the convergent gap, and Fig. (9b) shows the results for the diffuser gap.

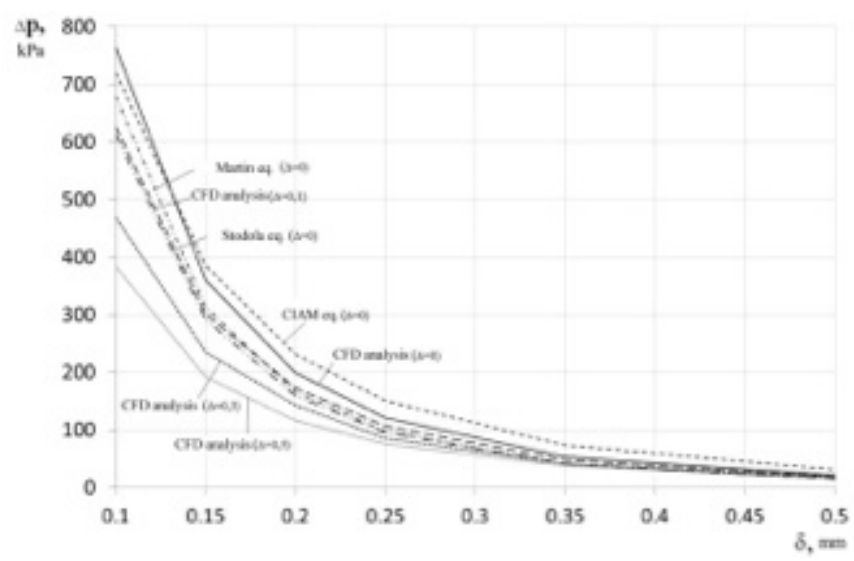

Fig. (7). Pressure drop dependence on the seal of the radial gap clearance.

(a) convergent labyrinth gap

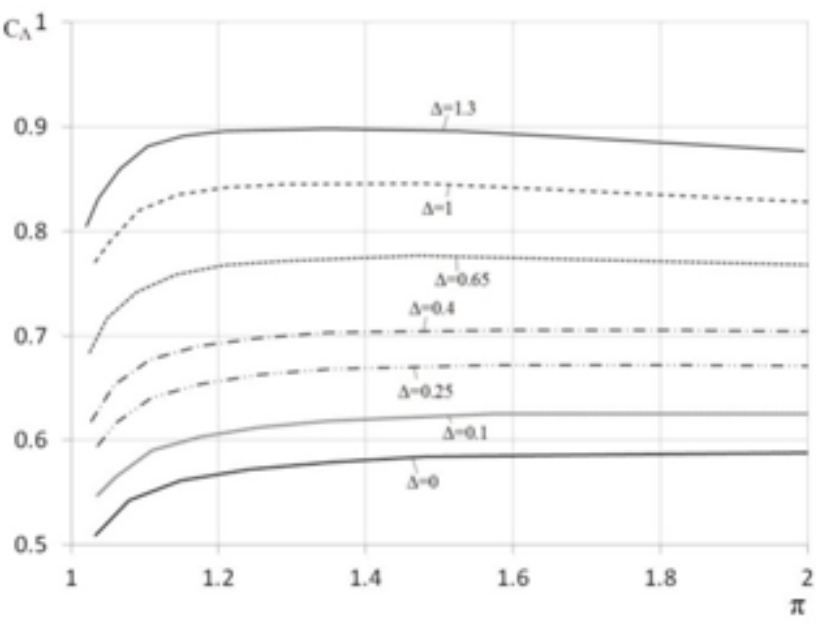

(b) diffuser labyrinth gap

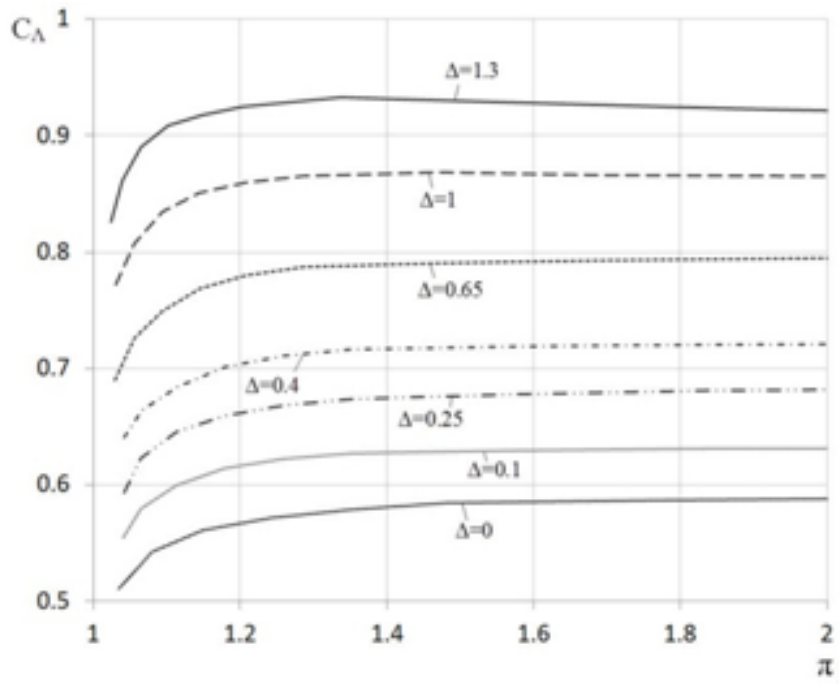

Fig. (8). Flow characteristics of seals for various taper values.

Fig. (9) shows that the taper coefficient $K_{\Delta}$ is almost independent of the differential pressure at small taper values. For the case of convergent gap with the taper increase the 
characteristics are stratified by differential stronger than for the diffusion gap case.

(a) convergent labyrinth gap

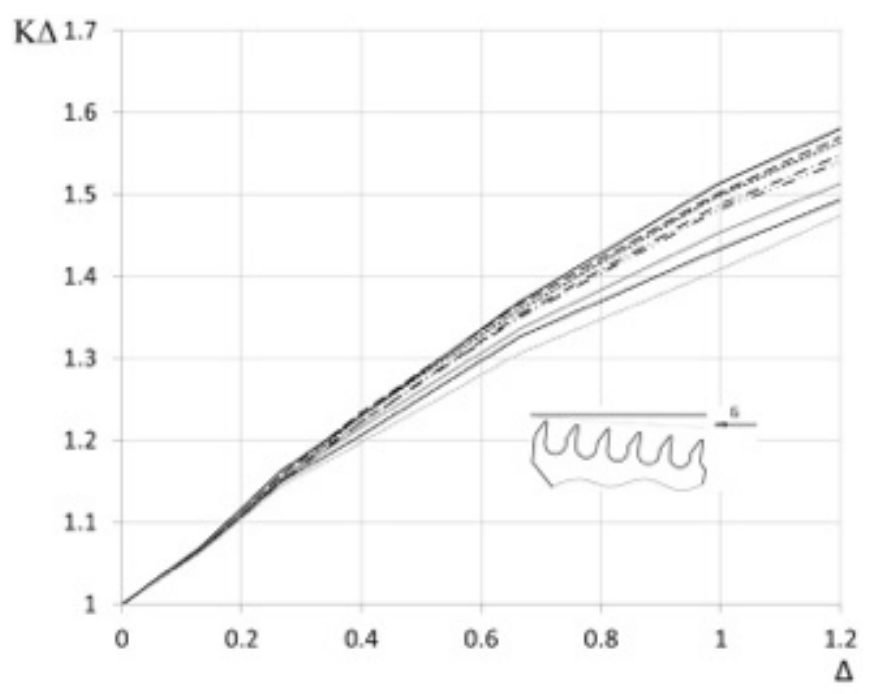

(b) diffuser labyrinth gap

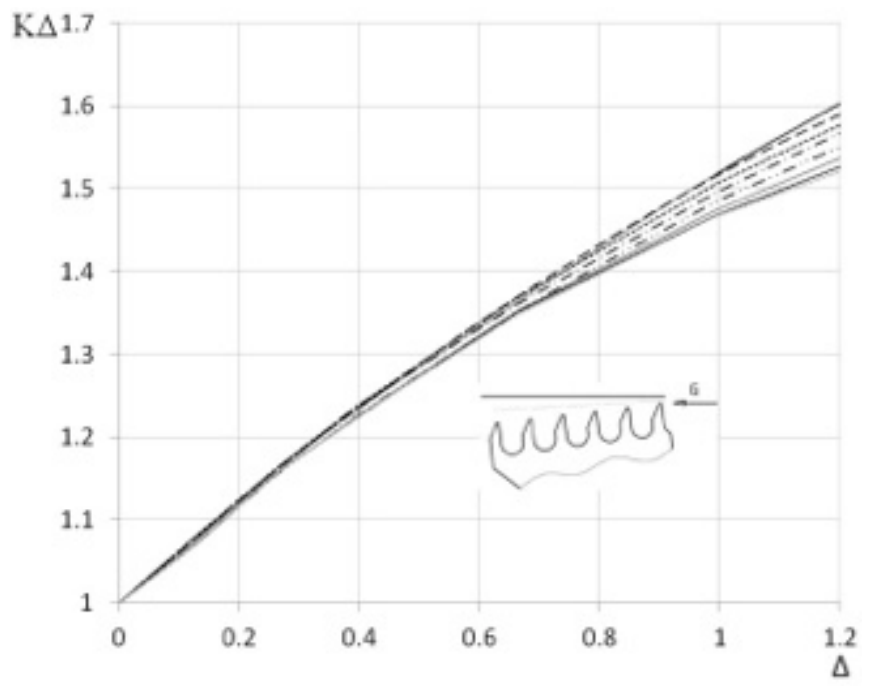

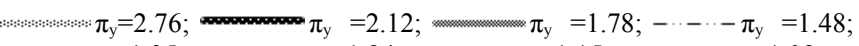

$--\pi_{\mathrm{y}}=1.35 ;-\cdots-\pi_{\mathrm{y}}=1.24 ;----\pi_{\mathrm{y}}=1.15 ;-\pi_{\mathrm{y}}=1.08$

Fig. (9). Taper correction factor dependence on the relative taper value for different pressure drops.

Characteristics showed by Fig. (9a) may be approximated with the following dependence

$K_{\Delta}=a \cdot\left(\frac{\delta_{\max }-\delta_{\min }}{\delta_{\min }}\right)^{2}+b \cdot\left(\frac{\delta_{\max }-\delta_{\min }}{\delta_{\min }}\right)+1$,

where

$a=0.067 \pi_{y}^{2}-0.176 \pi_{y}-0.022$

$b=-0.131 \pi_{y}+0.781$

The maximum approximation error makes $2.1 \%$. The characteristics presented by Fig. (9b) may be approximated with the following dependence
$K_{\Delta}=a \cdot\left(\frac{\delta_{\max }-\delta_{\min }}{\delta_{\min }}\right)^{2}+b \cdot\left(\frac{\delta_{\max }-\delta_{\min }}{\delta_{\min }}\right)+1$,

where

$a=0.027 \pi_{y}^{2}-0.138 \pi_{y}+0.008$

$b=0.005 \pi_{y}+0.622$

The maximum approximation error makes $2.3 \%$.

The total dependence, approximating the taper factor for taper small values $(\Delta<0.3)$ may be written as follows:

$K_{\Delta}=0.566 \cdot\left(\frac{\delta_{\max }-\delta_{\min }}{\delta_{\min }}\right)+1$.

The maximum approximation error is $1.9 \%$.

In the method of the engine secondary air systems the taper influence on the seal flow characteristics may be considered by the following algorithm.

1. The thermodynamic calculation of an engine is performed and the gas flow parameters in its assemblies are determined [24-26].

2. The hydraulic design of the air system with mounting values of the radial clearances is performed. The operational body parameters in the cavities are determined, including the pressure drop on the seal.

3. The engine thermal analysis is performed. The temperatures, which are used then as the load in the stress-strain analysis of the engine state are determined. The analysis is performed by successive approximations method as long as the channel wall temperature specified in the hydraulic calculation are not converged with the temperatures obtained during the thermal analysis.

4. The calculation of the stress-strain state. The minimum and maximum gap size is determined. The taper value is calculated.

5. When the taper value is less than 0.3 , the formula (3) is used to determine this coefficient. If the taper value is greater than 0.3 , the type of the labyrinth gap (convergent or cone) form is determined and then the taper factor is determined by the well-known differential pressure on the seal and by the taper parameter according to the formulas (1) or (2).

6. In the calculated dependences of seals introduced in the hydraulics calculation program, the taper factor or the value of the equivalent radial clearance are introduced. This clearance value is calculated via taper factor. Then an iterative calculation is carried out as long as the radial clearance and the taper in the calculation of stress-strain state are not converged to the clearance and taper set in the hydraulic model.

\section{CONCLUSION}

In this paper we analyzed the possible types of labyrinth gaps deformation during engine operation. For the conical gap case in the Fluent the correction factors were obtained to assess the seal characteristics. The evaluation of asymmetric 
deformations on the rotor and stator elements of a highpressure cascade the low-order values were obtained with respect to the components of the axially symmetric deformations, which allows in this case to ignore them to solve the problems of the seal characteristics determination. The approach described in this article allows to obtain the labyrinth seal characteristics with asymmetric deformation elements and taking into account the tooth insertion into the coatings.

\section{ABOUT THE AUTHORS}

First Author Andrei Tisarev, Junior researcher of Samara State Aerospace University. The author's major is Fluid and Mechanical Engineering.

Second Author Sergei Falaleev, Dr., Prof., Chief of department of construction and design of aircraft engines. The author's major is face contactless seals.

Third Author Alexandr Vinogradov, Dr., Dozent of department of construction and design of aircraft engines. The author's major is face contactless seals.

\section{CONFLICT OF INTEREST}

The author confirms that this article has no conflict of interest

\section{ACKNOLEDGEMENTS}

This work was supported by the Ministry of education and science of the Russian Federation in the framework of the implementation of the Program of increasing the competitiveness of SSAU among the world's leading scientific and educational centers for 2013-2020 years.

\section{REFERENCES}

[1] A.I. Golubev, L.A. Kondakov, V.B. Ovander, V.V. Gordeev, B.A. Furmanov and B.V. Karmugin."Seals and sealing equipment", Moscow, Mechanical Engineering, 1994.

[2] A.I. Belousov, S.V. Falaleev, A.S. Vinogradov and P.V. Bondarchuk,. "Problems of application of face gasodynamic seals in aircraft engines". Russian Aeronautics, vol.50 (4), pp. 390-394, 2007. doi: $10.3103 / \mathrm{S} 1068799807040083$

[3] A. Stodolaand P. Smith."Steam and Gas Turbines (translated by Loewenstein, L. C.)”, vol. 1, New York, 1945.

[4] H. M. Martin, "Labyrinth Packings". Engineering, pp. 35-36, 1908.

[5] B. Hodkinson. "Estimation of the Leakage through a Labyrinth Gland".Proceedings of the Institution of Mechanical Engineers, vol.141, pp. 283-288, 1939.

[6] A. Egli. "The Leakage of Steam through Labyrinth Seals". Transactions of the ASME, pp. 115-122, 1935.

[7] H.L. Stocker, D.M. Cox and G.F. Holle, "Aero-dynamic Performance of Conventional and Advanced Design Labyrinth Seals with Solid-Smooth". Abradable and Honeycomb Lands.NASA-CR-135307, 1977.

[8] V. Schramm, K. Willenborg, S. Kim and S. Wittig. "Influence of a Honeycomb-Facing on the Flow Through a Stepped Labyrinth Seal”. ASME Paper 2000-GT-0291, 2000.
[9] H. Zimmermann, A. Kammerer and K.H. Wolff. "Performance of Worn Labyrinth Seals". ASME Paper No. 94-GT-131, 1994.

[10] B.H. Song and S.J. Song. "Lateral forces from single gland rotor labyrinth seals in turbines". ASME Turbo Expo 2002, GT-200230335, 2002.

[11] A.M. Gamaland J.M. Vance. "Labyrinth seal leakage tests: tooth profile, tooth thickness, and eccentricity effects". ASME Turbo Expo 2007, GT2007-27223, 2007.

[12] H. Zimmermann and K.H. Wolff. "Air System Correlations : Part 1-Labyrinth Seals". ASME Paper 98-GT-206.

[13] H.L. Stocker, D.M. Cox and G.F. Holle."Aero-dynamic Performance of Conventional and Advanced Design Labyrinth Seals with Solid-Smooth". Abradable and Honeycomb Lands.NASA-CR-135307, 1998.

[14] P.A.E. Steward and K.A. Brasnett. "The Contribution of X-Ray to Gas Turbine Air Sealing Technology".AGARD-CP-237, 10.1$10.13,1978$.

[15] K.N. Chaadaev and D.K. Novikov. "Dynamics of a rigid rotor in the NK-14ST-10 engine free power turbine with sliding bearings". Russian Aeronautics, vol.52 (4), pp. 426-431, 2009.

[16] S. Falaleev, A. Vinogradov and P. Bondarchuk. "Influence research of extreme operate conditions on the face gas dynamic seal characteristics". Technische Akademie Esslingen International Tribology Colloquium Proceedings, vol.15, p. 208, 2006.

[17] Y. Muller, "Secondary air system model for integrated thermo mechanical analysis of a jet engine". Proceedings of ASME Turbo Expo 2008: Power for Land, Sea and Air, GT2008-50078, 2008.

[18] A. Peschiulli, D. Coutandin, M. Del Cioppoand \& M. Damasio. "Development of a numerical procedure for integrated multidisciplinary thermal-fluid-structural analysis of an aero engine turbine”. ASME Turbo Expo 2009, GT2009-59875, 2009.

[19] Y. Wang, C. Young, G. Snowsill and T. Scanlon."Study of Airflow Features through Step Seals in the Presence of Disengagement due to Axial Movement”, ASME Turbo Expo 2004, GT2004-53056, 2004.

[20] A.I. Belousov, S.V. Falaleev and A.S. Demura. On application of the theory of face seals with microgrooves to high-speed FV engine rotors. Russian Aeronautics, vol.52 (3), pp. 335-339. doi: 10.3103/S106879980903012X, 2009

[21] A.S. Vinogradov. "Seal design features for systems and units of aviation engines". Life Science Journal, vol.11(8), pp. 575-580, 2014.

[22] S.V. Falaleev. "Hydrodynamic characteristics of the face seal taking into account lubricant film breakdown, inertial forces and complex clearance form". Life Science Journal, vol.11(9), pp. 337343, 2014.

[23] I.B. Celik, U. Ghiaand P.J. Roache."Procedure for Estimation and Reporting of Uncertainty Due to Discretization in CFD Applications". Journal of Fluids Engineering, 2008.

[24] I. Zhdanov, S. Staudacher and S. Falaleev. "An advanced usage of meanline loss systems for axial turbine design optimisation". Proceedings of the ASME Turbo Expo 6 A. doi: 10.1115/GT201394323, 2013.

[25] N.T. Tikhonov and V.N. Matveev. "Experimental study of influence of upper and lower overlap magnitudes on efficiency of radial centripetal micro turbines with shrouded rotor". Soviet Aeronautic, vol.30 (4), pp. 120-123, 1987.

[26] S.K. Bochkarev, A.Ya. Dmitriev, V.V. Kulagin, S.V. Makeenko, V.V. Mosoulin and A.A. Mossoulin, "Experience and problems of computer aided thermogasdynamic analysis of testing results for gas-turbine engines with complex schemes". Izvestiya Vysshikh Uchebnykh Zavedenij. Aviatsionnaya Tekhnika, vol.2, pp. 68-70, 1993. 